\title{
Período Anterior à Interferência na Cultura da SOJA-RR EM Condições de Baixa, MÉdia e Alta Infestação ${ }^{1}$
}

\author{
Period before Interference in Soybean-RR Crop Under Low, Medium and High Infestation Level \\ Conditions
}

\author{
SILVA, A.F. ${ }^{2}$, CONCENÇO, G. ${ }^{2}$, ASPIAZÚ, I. ${ }^{2}$, FERREIRA, E.A. ${ }^{2}$, GALON, L. ${ }^{2}$, FREITAS, M.A.M. ${ }^{3}$, \\ SILVA, A.A. ${ }^{4}$ e FERREIRA, F.A. ${ }^{4}$
}

\begin{abstract}
RESUMO - Este trabalho foi conduzido com o objetivo de determinar o período anterior à interferência (PAI) das plantas daninhas na cultura da soja, cv. BRS 243-RR, cultivada em condições de baixa, média e alta infestação. O delineamento experimental foi em blocos ao acaso, com dez tratamentos, constituidos por periodos crescentes de convivência das plantas daninhas com a cultura $(0,0-5,0-10,0-15,0-21,0-28,0-35,042,0-49$ e $0-125$ dias). Na área de baixa infestação, as principais espécies infestantes foram Brachiaria plantaginea, Ipomoea nil e Euphorbia heterophylla. Nas áreas de média e alta infestação, destacaram-se Brachiaria plantaginea, Ipomoea nil, Digitaria horizontalis e Cyperus rotundus. Considerando 5 e $10 \%$ de tolerância na redução da produtividade da soja, conclui-se que em áreas de baixa, média e alta infestação de plantas daninhas os períodos anteriores à interferência (PAI) foram de: 17 e 24 dias após a emergência (DAE), 11 e 15 DAE e 11 e 16 DAE, respectivamente. A interferência das plantas daninhas na cultura durante todo o ciclo reduziu o rendimento de grãos da soja, em média, em 73\% (área de baixa infestação), 82\% (área de média infestação) e 92,5\% (área de alta infestação).
\end{abstract}

Palavras-chave: competição, períodos críticos de competição, Glycine max.

ABSTRACT - The aim of this study was to evaluate the period before weed interference in soybean culture, $c v$. BRS 243-RR, under low, medium and high weed density. The experimental design was arranged in complete randomized blocks, and the treatments consisted of increasing periods of weed control (0, 0-5, 0-10, 0-15, 0-21, 0-28, 0-35, 0-42, 0-49 and 0-125 days). In low weed infestation area the main weed species were: Brachiaria plantaginea, Ipomoea nil, Euphorbia heterophylla. In medium and high infestation areas, Brachiaria plantaginea, Ipomoea nil, Digitaria horizontalis and Cyperus rotundus were the most frequent weeds. Considering $5 \%$ and $10 \%$ of tolerance of soybean grain yield reduction, it was concluded that the period before interference was 17 and 24 days after emergence (DAE) in low infestation, area 11 and 15 DAE in medium infestation area and 11 and 16 DAE in high infestation area. Weed interference during the full crop cycle reduced soybean grain yield in $73 \%, 82 \%$ and $92 \%$, for low, medium and high weed density, respectively.

Keywords: competition, critical periods of competition, Glycine max.

\section{INTRODUÇÃO}

A soja (Glycine max), sem dúvida, é destaque entre as principais oleaginosas do mundo. Nos últimos anos, principalmente com a abertura de novas áreas sob vegetação de cerrado, o Brasil passou a ser o segundo maior produtor do mundo, com produção total superior a 58 milhões de toneladas de grãos, em área estimada de 21,24 milhões de hectares

1 Recebido para publicação em 3.9.2007 e na forma revisada em 18.2.2009.

2 Engo-Agrọ , aluno do Programa de Pós-Graduação em Fitotecnia da Universidade Federal de Viçosa - UFV, 36570-000 Viçosa-MG, <afsagro@gmail.com>; ${ }^{3}$ Estudante de graduação em Agronomia - UFV; ${ }^{4}$ Engo-Agro ${ }^{\circ}$, D.Sc., Prof. do Dep. de Fitotecnia - UFV (Bolsista do CNPq). 
(CONAB, 2009). Cultivada em praticamente todo o território nacional e com média de rendimento que é recorde mundial, a soja é considerada a cultura mais importante do País. Nessa cultura são consumidos aproximadamente $30 \%$ de todos os produtos agrícolas comercializados para proteção de plantas no Brasil, estimado em mais de U\$ 2,1 bilhões, sendo a maior parte constituída pelos herbicidas (ANDEF, 2006).

Após liberação oficial da soja transgênica resistente ao glyphosate em 2005, estão ocorrendo profundas mudanças nos sistemas de manejo de plantas daninhas nessa cultura, tendo em vista que vários produtos ou combinações destes estão sendo substituídos por um único ingrediente ativo: o glyphosate (Gazziero, 2005). Esse herbicida, por apresentar uma série de vantagens - como: ter amplo espectro de ação; ser de simples aplicação; não possuir efeito residual no solo; apresentar alta seletividade à soja; controlar espécies e biótipos tolerantes ou resistentes a outros mecanismos de ação; ser de baixo custo e mais eficiente que os demais herbicidas existentes no mercado mundial - representa um grande atrativo aos produtores (Silva et al., 2007).

Em decorrência de todos esses pontos positivos, o cultivo da soja resistente ao glyphosate é a tecnologia de aceitação mais rápida na história da agricultura mundial. Outro fator importante que contribui para a rápida aceitação da cultura da soja resistente ao glyphosate foi o fato de esse herbicida ser eficiente no controle de plantas daninhas em estádios avançados de desenvolvimento, o que não ocorre com os demais pós-emergentes recomendados para essa cultura (Rodrigues \& Almeida, 2005).

Os fatores que podem afetar o grau de interferência da comunidade infestante sobre uma cultura dependem de aspectos ligados à espécie daninha, densidade e distribuição e à própria cultura (cultivar, espaçamento e densidade de semeadura) (Pitelli, 1985). O grau de interferência depende também da época e do tempo em que a cultura e a comunidade infestante permanecem juntas, além das condições edafoclimáticas e do manejo utilizado.

O grau de competição entre plantas daninhas e cultura pode ser alterado em função do período em que a comunidade estiver disputando determinado recurso. No início do ciclo de desenvolvimento, a cultura e as plantas daninhas podem conviver por um determinado periodo sem que estas venham a afetar a produção quantitativa ou qualitativamente da cultura. Essa fase é denominada período anterior à interferência (PAI), em que o meio é capaz de fornecer os recursos de crescimento necessários à comunidade infestante e à cultura (Velini, 1992). Teoricamente, o manejo de plantas daninhas deveria ser iniciado no final do PAI, pois os efeitos da interferência são irreversiveis, não havendo recuperação do desenvolvimento ou da produtividade após retirada do estresse causado pela presença das plantas daninhas (Kozlowski, 2002). Assim, em termos de manejo de plantas daninhas, o PAI torna-se o período de maior importância, a partir do qual a produtividade é significativamente afetada.

No manejo de plantas daninhas em culturas convencionais, o PAI sempre teve importância acadêmica e raramente servia para orientar as aplicações de herbicidas em pós-emergência, uma vez que o final desse período sempre ocorria em épocas em que as plantas daninhas já haviam passado da fase de maior suscetibilidade a grande parte dos produtos disponiveis no mercado.

Com a introdução da soja resistente ao glyphosate, o PAI passou a ter importância prática muito maior, pois possibilita a utilização mais correta do herbicida em pós-emergência, visto que este atuará independentemente do estádio de desenvolvimento da planta daninha, permitindo a sua eliminação no momento desejado.

Objetivou-se com este estudo determinar o período anterior à interferência de plantas daninhas em três condições de infestação (baixa, média e alta), em soja, cv. BRS 243-RR.

\section{MATERIAL E MÉTODOS}

O experimento foi conduzido nos sistemas de plantio convencional e direto, em um Argissolo Vermelho-Amarelo câmbico, no período de novembro de 2006 a março de 2007, em Coimbra-MG. A área de baixa infestação correspondeu ao sistema de plantio direto; as áreas de média e alta infestação foram 
conduzidas em sistema convencional de semeadura. Dez dias após a emergência (DAE) da soja, as áreas de baixa, média e alta infestação apresentavam, respectivamente, densidade média de 0-30, 31-150 e mais de150 plantas daninhas por metro quadrado. A análise das amostras de solo, coletadas antes da instalação do experimento na área destinada ao plantio convencional, apresentou as seguintes características químicas: $\mathrm{pH}$ em água de 5,0; 1,01 dag $\mathrm{kg}^{-1}$ de matéria orgânica; 9,6 $\mathrm{mg} \mathrm{dm}^{3}$ de $\mathrm{P} ; 50 \mathrm{mg} \mathrm{dm}^{-3}$ de K; e Ca, $\mathrm{Mg}, \mathrm{H}$ + Al e CTC de 2,0; 0,5;2,5; e 5,12 $\mathrm{cmol}_{\mathrm{c}} \mathrm{dm}^{-3}$, respectivamente. Em plantio direto, os valores corresponderam a $\mathrm{pH}$ em água de 5,0; 1,07 dag $\mathrm{kg}^{-1}$ de matéria orgânica; $7,1 \mathrm{mg} \mathrm{dm}^{-3}$ de $\mathrm{P} ; 59 \mathrm{mg} \mathrm{dm}^{-3}$ de $\mathrm{K}$; e Ca, $\mathrm{Mg}, \mathrm{H}+\mathrm{Al}$ e CTC de 2,$3 ; 0,6 ; 2,6$; e $5,65 \mathrm{cmol}_{\mathrm{c}} \mathrm{dm}^{-3}$, respectivamente.

Antecedendo à instalação dos ensaios, foi realizada a dessecação química com os herbicidas glyphosate e 2,4-D (1.440 + $470 \mathrm{~g} \mathrm{ha}^{-1}$, respectivamente) em mistura no tanque, dez dias antes da semeadura. No ensaio referente ao plantio convencional, essa vegetação foi incorporada pelo preparo mecânico do solo com uma aração e duas gradagens, sete dias antes da semeadura, enquanto no plantio direto ela permaneceu na superficie do solo.

O cultivar de soja utilizado foi o BRS 243-RR, semeado no espaçamento de $0,50 \mathrm{~m}$ entre linhas, depositando-se em média 13,5 sementes por metro linear. Na adubação de semeadura foram utilizados $400 \mathrm{~kg} \mathrm{ha}^{-1}$ da formulação 8-28-16 (N-P-K) na linha de plantio. Os dados climatológicos do período de condução do ensaio estão apresentados na Figura 1.

Em ambos os sistemas de cultivo a cultura da soja ficou em convivência com as plantas daninhas por diferentes períodos do seu ciclo de desenvolvimento: $0,5,10,14,21,28,35$, 42, 49 e 125 dias (todo o ciclo da cultura), totalizando assim dez tratamentos em cada nível de infestação. Após o término de cada período inicial de convivência, foi realizado o controle das plantas daninhas até a colheita, com aplicações de glyphosate sempre que necessário, para manter as parcelas no limpo. $\mathrm{O}$ delineamento experimental adotado foi em blocos casualizados, com dez tratamentos e quatro repetições. As parcelas foram constituídas por seis linhas de 3,0 m de comprimento, com espaçamento de 0,5 m de largura. A área útil para avaliação foi constituída das quatro

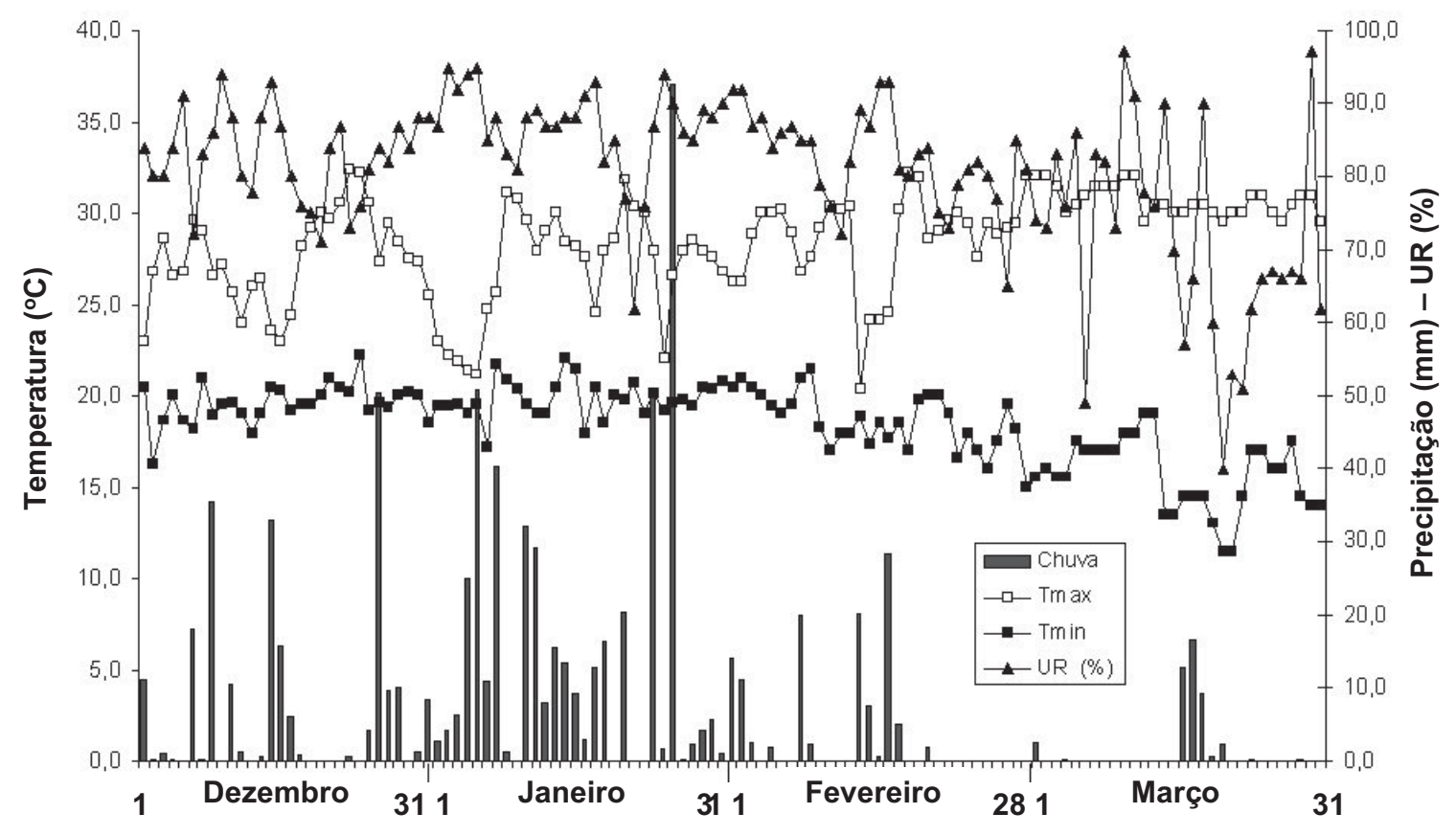

Figura 1 - Dados climáticos observados na área experimental durante a realização do experimento: precipitação pluvial, temperaturas máxima e mínima e umidade relativa do ar. 
linhas centrais e teve como bordadura uma linha de plantio de cada lado e 0,5 $\mathrm{m}$ de cada uma das extremidades, perfazendo $4 \mathrm{~m}^{2}$.

As avaliações da densidade e da matéria seca das plantas daninhas foram realizadas no final de cada período de convivência. Essas avaliações foram feitas com o lançamento aleatório de um quadrado de 0,25 m de lado, por quatro vezes, na área útil de cada parcela. As partes aéreas das plantas daninhas foram coletadas e separadas por espécie, determinando-se os valores de densidade e massa seca. A massa seca foi obtida pela secagem em estufa com ventilação forçada de ar, a $70{ }^{\circ} \mathrm{C}$, até atingir massa constante. A colheita da cultura foi realizada coletando-se manualmente todas as plantas de soja da área útil de cada parcela. Elas foram passadas por trilhadeira mecânica para determinação da produtividade $\left(\mathrm{kg} \mathrm{ha}^{-1}\right)$ de grãos, os quais tiveram a umidade padronizada para $13 \% \mathrm{~m} / \mathrm{m}$.

Todos os dados foram verificados quanto à normalidade e homogeneidade e submetidos à análise de variância pelo teste $\mathrm{F}$. Em caso de significância, os dados foram submetidos à análise de regressão. A escolha dos modelos foi baseada no fenômeno biológico, no valor do coeficiente de determinação $\left(R^{2}\right)$ e na significância da análise de variância da regressão.

Com base nas curvas das equações de regressão, foi determinado o período anterior à interferência das plantas daninhas em cada nível de infestação, para os níveis arbitrários de tolerância de 5 e 10\% de redução na produtividade de grãos de soja, em relação ao tratamento mantido na ausência das plantas daninhas.

\section{RESULTADOS E DISCUSSÃO}

Ocorreu elevada precipitação pluvial na área experimental durante o desenvolvimento da cultura da soja (Figura 1), o que leva a acreditar que a competição tenha se estabelecido principalmente por luz, nutrientes e $\mathrm{CO}_{2}$. Segundo Radosevich et al. (1997), em ecossistemas agrícolas, a cultura e as plantas daninhas possuem suas demandas por água, luz, nutrientes e $\mathrm{CO}_{2}$. Todavia, a competição por esses fatores de crescimento apenas vai se estabelecer quando pelo menos um deles está disponível em quantidade insuficiente.
Quanto aos efeitos dos períodos de convivência das plantas daninhas com a soja, em área de baixa infestação (Figura 2A), verificouse aumento linear na densidade de plantas ao longo dos períodos de avaliação. Isso se deveu à baixa densidade de plantas infestantes na área, não caracterizando a competição inter e intraespecífica por espaço. Já de acordo com o modelo de regressão adotado nas áreas de média e alta infestação (Figura 2B, C, respectivamente), observou-se decréscimo na densidade da comunidade infestante a partir de 33 dias após a emergência (DAE) da cultura na área de média infestação e de 28 DAE na área de alta infestação. Isso decorreu da mortalidade de plantas devido à competição pelos recursos do meio.

Na Figura 3 são apresentados os resultados de massa seca acumulada pela comunidade infestante, em função dos periodos iniciais de convivência nos diferentes níveis de infestação. Observou-se que o acúmulo de massa seca se manteve em niveis baixos por um período inicial e, posteriormente, apresentou grande incremento. Resultado semelhante foi encontrado por Spadotto et al. (1992), Freitas et al. (2004) e Brighenti et al. (2004), em que o acúmulo de massa seca das plantas daninhas se manteve em niveis baixos até 20 dias da competição inicial. Após esse período ocorreu grande incremento na massa seca até por volta dos 50 dias, havendo pequeno decréscimo de massa a partir desta data.

Nas áreas experimentais de média e alta infestação, observou-se que, apesar da redução nas densidades de planta ocorrida ao longo do período de avaliação, houve aumento da massa da comunidade infestante. Segundo Radosevich et al. (1997), à medida que aumenta a densidade e ocorre o desenvolvimento das plantas daninhas, especialmente daquelas que germinaram e emergiram no início do ciclo da cultura, intensifica-se a competição inter e intraespecífica, de modo que as plantas daninhas mais altas e desenvolvidas tornamse dominantes, ao passo que as menores podem ser suprimidas ou morrem. Esse comportamento de uma comunidade infestante explica a redução da densidade de plantas com o aumento da massa seca durante o desenvolvimento da cultura. 

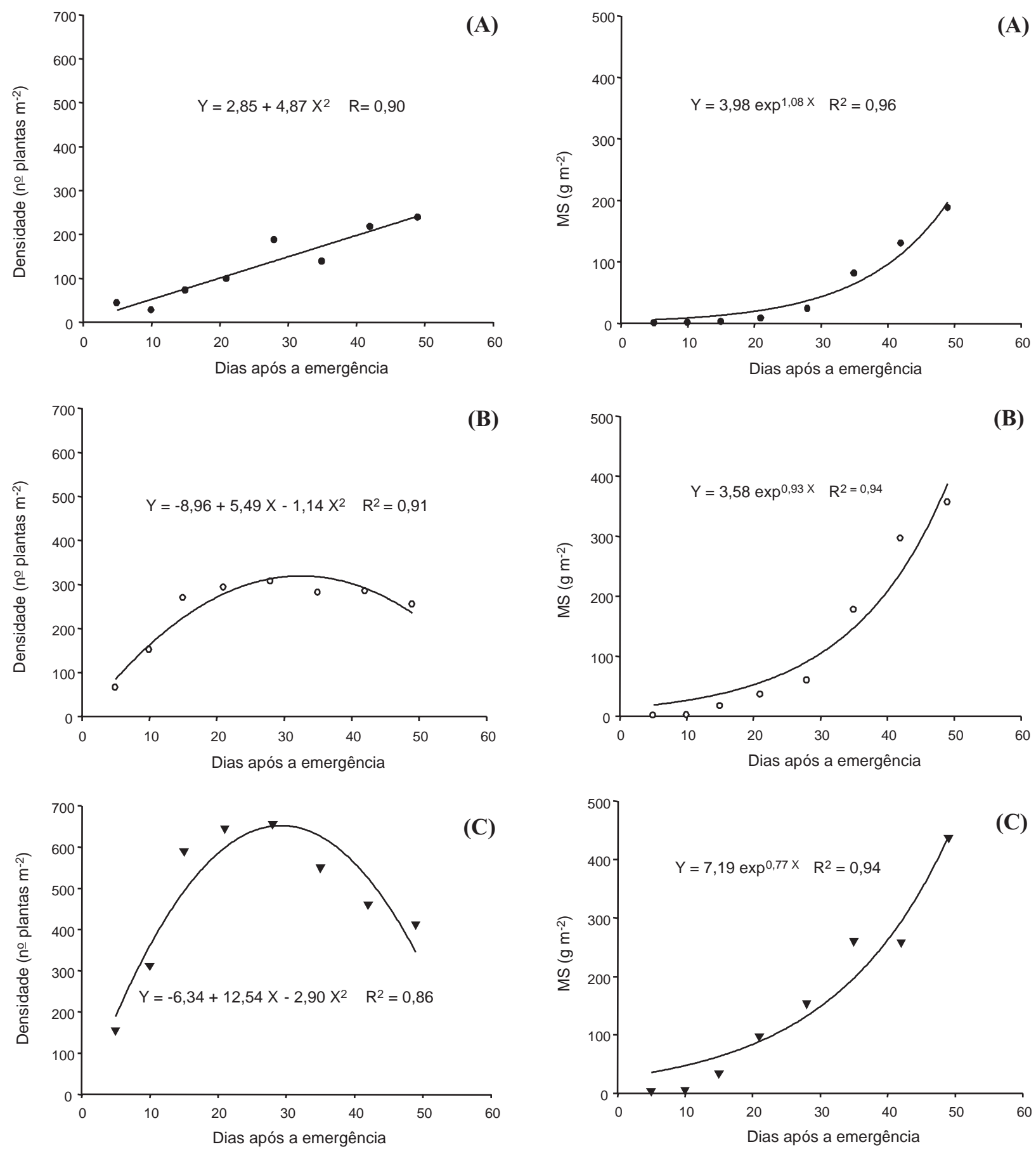

Figura 2 - Densidade da comunidade infestante em diferentes épocas após a emergência da soja cultivada em áreas de baixa (A), média (B) e alta infestação (C) de plantas daninhas.

As espécies daninhas mais importantes na comunidade infestante, na área de baixa infestação, foram: Brachiaria plantaginea, Ipomoea nil, Euphorbia heterophylla e outras

Figura 3 - Massa seca da comunidade infestante em diferentes épocas após a emergência da soja cultivada em áreas de baixa (A), média (B) e alta infestação (C) de plantas daninhas.

(espécies constituídas praticamente por dicotiledôneas de pequeno porte) (Figura 4). Observou-se que as densidades da comunidade infestante de E. heterophylla e Ipomoea nil 
praticamente se mantiveram constantes durante todo o período de avaliação, ao contrário de $B$. plantaginea, que apresentou leve crescimento linear ao longo do tempo, enquanto outras mostraram crescimento linear um pouco mais acentuado. Contudo, quando se compara a densidade com a massa seca dessas plantas (Figura 5), observa-se que $B$. plantaginea apresentou acúmulo de massa exponencial ao longo do período de avaliação, enquanto outras tiveram o seu crescimento suprimido, apresentando baixo acúmulo de massa seca.

As plantas daninhas mais importantes na comunidade infestante nas áreas de média e alta infestação foram: Brachiaria plantaginea,

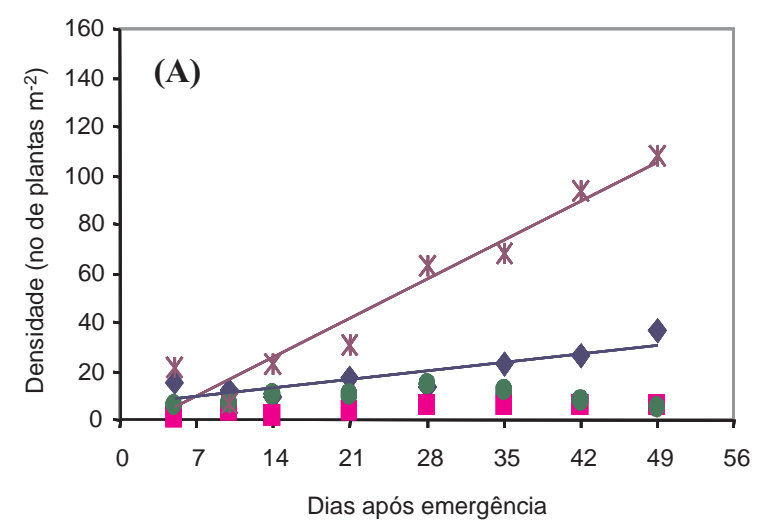

BP-Linear. $\hat{Y}=2,28 x-6,21 R^{2}=0,75^{\star *}$;

* Outras - Linear $\hat{Y}=0,50 x+6,19 R^{2}=0,94^{* *}$;

** Significativo pelo teste $\mathrm{F}(\mathrm{P}<0,01)$

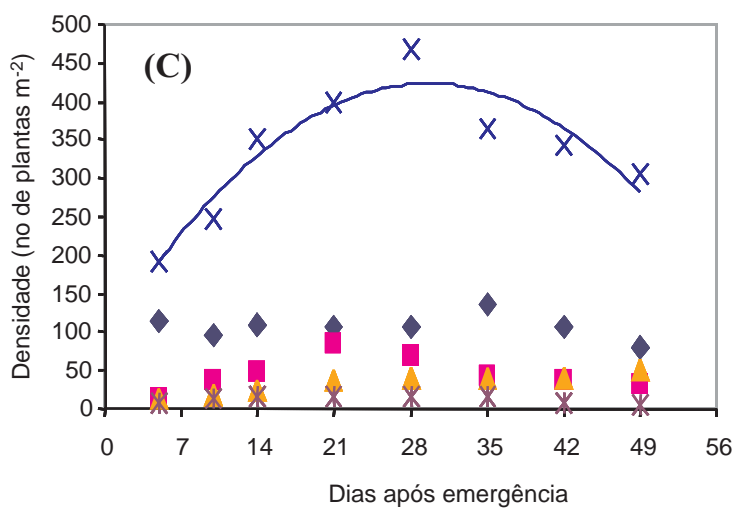

$X$ CYRO - Polinômio $\hat{Y}=-0,38 x^{2}+22,58 x+88,1 R^{2}=0,86^{* *}$

** Significativo pelo teste $\mathrm{F}(\mathrm{P}<0,01)$
Ipomoea nil, Digitaria horizontalis e Cyperus rotundus, entre outras (Figura 4). Observou-se na área de média infestação que a única espécie a apresentar aumento significativo na sua densidade ao longo do período de avaliação foi $C$. rotundus, que tendeu a ter crescimento linear, ao passo que as demais plantas da comunidade infestante mantiveram sua população constante. Quanto ao acúmulo de massa seca das plantas daninhas dessa área, $C$. rotundus e $B$. plantaginea se destacaram, suprimindo as demais espécies (Figura 5). Esta última, mesmo mantendo sua população praticamente constante, apresentou grande acúmulo de massa. Fato semelhante foi observado por Meschede et al. (2002), segundo

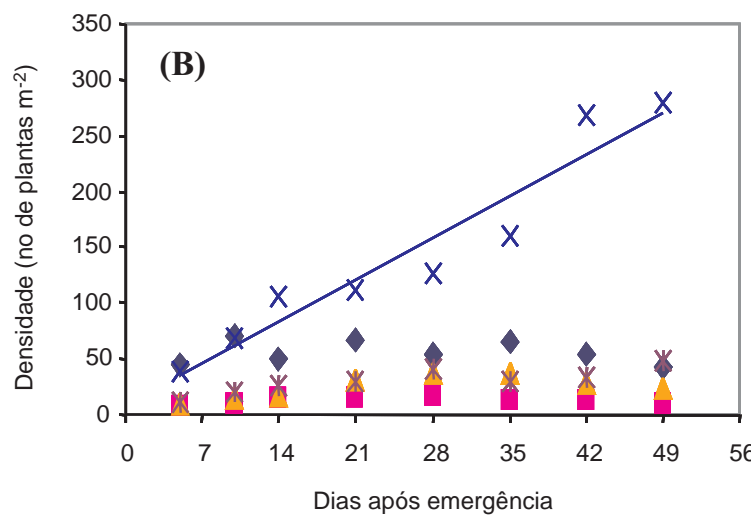

$X$ CYRO - Linear $\hat{Y}=5,33 x+9,01 R^{2}=0,92^{* *}$

${ }^{* *}$ Significativo pelo teste $\mathrm{F}(\mathrm{P}<0,01)$

\section{Legendas}

$\checkmark$ BP - Brachiaria plantaginea

$\mathrm{X}$ CYRO- Cyperus rotundus

$\triangle \mathrm{DH}$ - Digitaria horizontalis

- EH- Euphorbia heterophylla

IP- Ipomoea sp.

* Outras

Figura 4 - Densidade das principais espécies daninhas em diferentes épocas após a emergência da soja cultivada em áreas com (A) baixa infestação (plantio direto), (B) média infestação (plantio convencional) e (C) alta infestação (plantio convencional) de plantas daninhas. 

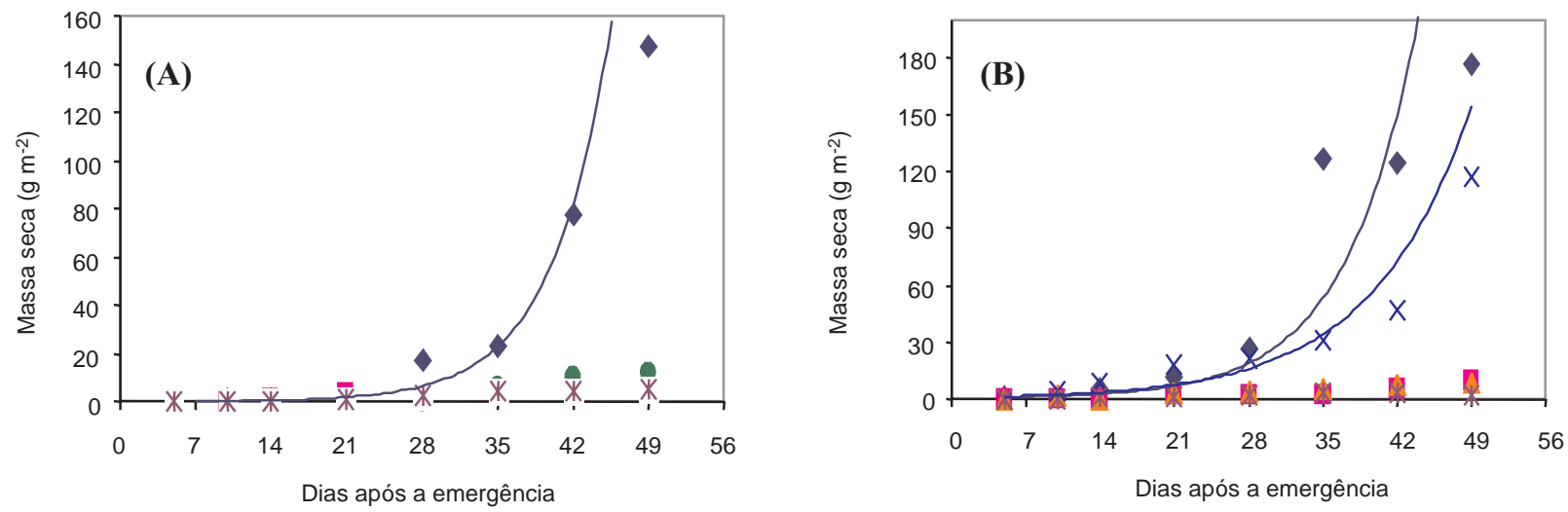

- BP - Expon. $\hat{Y}=0,0864 \mathrm{e}^{0,1608 x} \mathrm{R}^{2}=0,98^{* *}$

** Significativo pelo teste $F(P<0,01)$

$$
\begin{aligned}
& \text { BP - Expon. } \hat{Y}=0,5362 e^{0,1323 x} R^{2}=0,94^{* *} \\
& \text { X CYRO - Expon. } \hat{Y}=0,7751 e^{0,108 \times} R^{2}=0,78^{* *} \\
& { }^{* *} \text { Significativo pelo teste } F(P<0,01)
\end{aligned}
$$

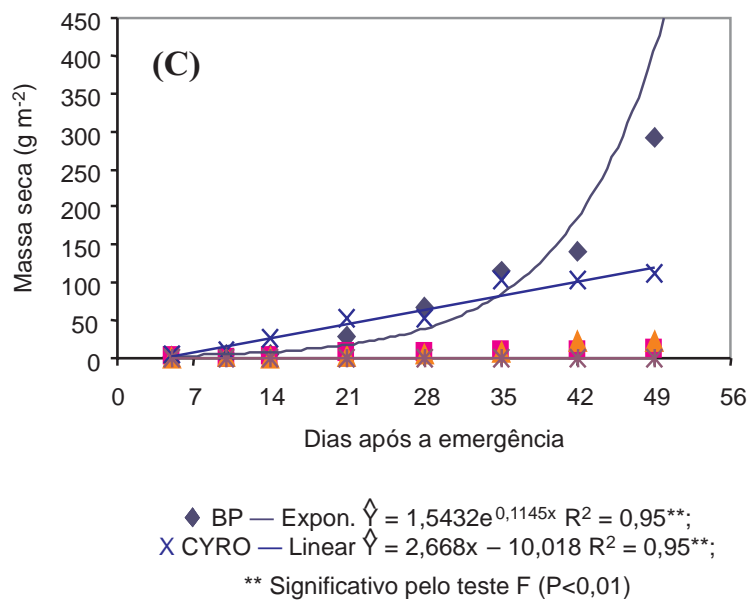

\section{Legendas}

$\checkmark \mathrm{BP}$ - Brachiaria plantaginea

$\mathrm{X}$ CYRO- Cyperus rotundus

$\triangle$ DH - Digitaria horizontalis

- EH- Euphorbia heterophylla

- IP- Ipomoea sp.

* Outras

Figura 5 - Massa seca das principais espécies daninhas em diferentes épocas após a emergência da soja cultivada em áreas com (A) baixa infestação (plantio direto), (B) média infestação (plantio convencional) e (C) alta infestação (plantio convencional) de plantas daninhas.

os quais algumas espécies de plantas daninhas continuam a crescer mesmo após a estabilização da densidade, suprimindo outras espécies em determinadas fases do ciclo da cultura, quando a elas não são suprimidos os recursos do meio para seu crescimento.

Quando se analisou o desenvolvimento das plantas daninhas na área de alta infestação, observou-se aumento significativo da população de C. rotundus até os $28 \mathrm{DAE}$, constatandose, após esse período, redução de sua densidade na área. Isso pode ser explicado pela competição com as outras espécies que ocorreram em maiores densidades que nas outras áreas, sobretudo a competição por luz, que passou a ser limitante para essa espécie, em razão da elevada densidade e do rápido crescimento, e para de $B$. plantaginea, principal infestante da área, a qual apresentou acúmulo de massa maior do que o de todas as outras espécies (Figura 5). Esses resultados indicam que esta espécie foi a mais competitiva em todos os niveis de infestação, o que justifica o fato de ser considerada uma das gramineas infestantes mais agressivas em culturas anuais no Brasil.

B. plantaginea, em condições de alta temperatura e intensidade luminosa, como observado durante a condução do experimento, por apresentar metabolismo $\mathrm{C} 4$, tende a mostrar crescimento acelerado. 
Todavia, isso não aconteceu com as espécies $C$. rotundus e $D$. horizontalis, que, apesar de apresentarem o mesmo metabolismo, têm taxa de acúmulo de massa inicial mais lenta do que $B$. plantaginea, sendo, por isso, sombreadas por esta espécie quando em competição.

A presença de $B$. plantaginea afeta diretamente o rendimento das culturas. Em condições de solo fértil, o desenvolvimento pode ser tão vigoroso que uma planta por $\mathrm{m}^{2}$ chega a afetar $50 \%$ do rendimento da soja. O prejuízo varia conforme o porte da cultura e a duração do período de competição. Na colheita, têm-se novos prejuízos, pois a invasora apresenta ciclo mais longo do que o das culturas anuais e a presença de grande massa foliar pode dificultar ou impedir o funcionamento das colhedoras, além de aumentar a umidade dos grãos (Kissmann, 1997).

Os efeitos da interferência são irreversíveis, não havendo recuperação do desenvolvimento ou da produtividade após retirada do estresse causado pela presença das plantas daninhas (Kozlowski et al., 2002). Diversos valores já foram determinados para o PAI na literatura para a cultura da soja, pois a interferência é influenciada por fatores ligados à própria cultura (espécie ou variedade, espaçamento e densidade de plantio), à época e extensão do período de convivência e aos aspectos característicos das plantas daninhas (composição específica, densidade e distribuição) (Pitelli, 1985). Mello et al. (2001), verificando a interferência das plantas daninhas na cultura da soja, cultivar UFV-16, semeadas em dois espaçamentos $(30$ e $60 \mathrm{~cm})$, determinaram PAI de 7 e $18 \mathrm{DAE}$, respectivamente, admitindo perda de $2 \%$. Nepomuceno et al. (2007), avaliando a interferência das plantas daninhas nos sistemas de semeadura direta (cultivar CD 201) e no sistema de semeadura convencional (cultivar M-SOY-6101), chegaram a um PAI de 33 e 34 DAE, respectivamente, considerando perda de $5 \%$. Carvalho et al. (2001), verificando os períodos de interferência de plantas daninhas na cultura da soja, cultivar IAC-11, constataram um PAI de 49 DAE, enquanto Meschede et al. (2002), trabalhando com a soja, cultivar BRS-133, encontraram PAI de 11 DAE. No entanto, a maioria dos estudos sobre competição entre plantas daninhas e culturas tem focalizado somente a ocorrência e o impacto da competição na produção da cultura, sem examinar as características das plantas e os mecanismos que estão associados à competitividade (Radosevich et al., 1997). Contudo, trabalhos mais recentes têm apresentado algumas justificativas para a baixa produtividade observada nas culturas quando em competição com espécies de plantas daninhas. Bidens pilosa e Leonurus sibiricus, desenvolvendo-se juntamente com plantas de café em fase inicial, podem reduzir o conteúdo relativo de N-P-K nos tecidos dessa cultura para 28-39-28\% e $14-29-21 \%$ do total, respectivamente (Ronchi et al., 2003). Para Procópio et al. (2005), a elevada capacidade competitiva da espécie Desmodium tortuosum nas culturas da soja e do feijão pode ter como contribuição o maior acúmulo de nutrientes por essa planta daninha, principalmente o fósforo.

Quanto aos resultados deste trabalho, observam-se na Figura 6 as curvas referentes à produtividade de soja, em função dos períodos de controle das plantas daninhas. Considerando-se uma perda de produtividade 5 e $10 \%$ desse cultivar, o periodo anterior à interferência (PAI) foi de 17 e 24 dias, respectivamente, na área de baixa infestação (Figura 6A). Considerando perda de 5\% (PAI de 17 dias), a comunidade infestante apresentava uma densidade de 80 plantas $\mathrm{m}^{-2}$ e massa seca de $2,26 \mathrm{~g} \mathrm{~m}^{-2}$; quando se admitiu perda de 10\% (PAI de 24 dias), a densidade foi de 116 plantas $\mathrm{m}^{-2}$ e a massa seca de $16,35 \mathrm{~g} \mathrm{~m}^{-2}$. A interferência das plantas daninhas durante todo o ciclo da cultura chegou a reduzir, nessas condições, a produtividade da soja em até $73 \%$. No que se refere aos efeitos na área de média infestação, admitindo perda de $5 \%$ (PAI de 11 dias), observou-se densidade de 178 plantas $\mathrm{m}^{-2}$ e massa seca de $0,49 \mathrm{~g} \mathrm{~m}^{-2}$. Entretanto, para essa condição, admitindo perda de $10 \%$, o PAI foi de 15 dias, observandose densidade de 226 plantas $\mathrm{m}^{-2}$ e massa seca de $4,98 \mathrm{~g} \mathrm{~m}^{-2}$ (Figura 6B). A interferência das plantas daninhas, nesse caso, durante todo o ciclo da cultura chegou a reduzir a produtividade da soja em até $82 \%$. Já para os efeitos na área de alta infestação, apesar da maior densidade de plantas daninhas e massa, verificaram-se valores de PAI próximos àqueles observados para média infestação (PAI de 11 e 16 dias), considerando perda de $5 \%$ 

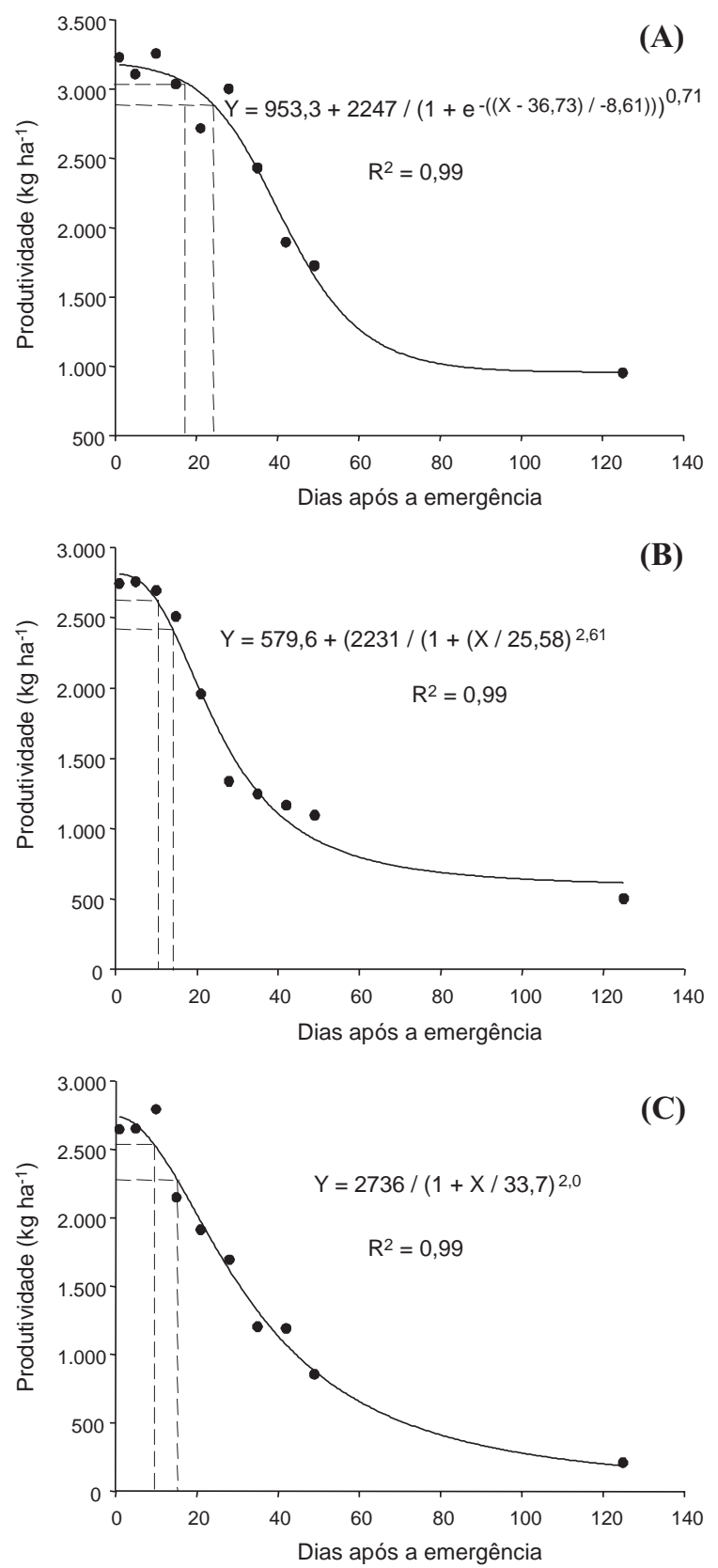

Figura 6 - Produtividade da soja, cv BRS 243 -RR, em função de períodos iniciais crescentes na presença de plantas daninhas em áreas de (A) baixa infestação, (B) média infestação e (C) alta infestação.

(Figura 6C). Nessas condições, a interferência das plantas daninhas durante todo o ciclo da cultura reduziu a produtividade da soja em até $92,5 \%$.

Com base nos valores dos PAIs encontrados, observa-se que, em densidade muito baixa, o rendimento da população é determinado pelo número de indivíduos. Conforme a densidade de plantas é aumentada, o potencial de fornecimento de recursos pelo ambiente se torna limitante, isto é, o rendimento passa a se tornar independente da densidade de plantas a partir de determinado nível de infestação (Radosevich et al., 1997). Esse fato se verificou neste trabalho, pois a densidade de plantas encontrada na área de média infestação teve efeito equivalente ao da alta infestação, apesar da maior densidade de espécies infestantes encontrada na área.

Para as condições deste trabalho, considerando 5 e $10 \%$ de tolerância na redução da produtividade da soja, conclui-se que, em áreas de baixa, média e alta infestação de plantas daninhas, os PAIs foram de 17 e 24 dias após a emergência(DAE), 11 e 15 DAE e 11 e 16 DAE, respectivamente. A interferência das plantas daninhas na cultura durante todo o ciclo reduziu o rendimento de grãos da soja, em média, 73\% (área de baixa infestação), 82\% (área de média infestação) e 92,5\% (área de alta infestação).

\section{LITERATURA CITADA}

ASSOCIAÇÃO NACIONAL DE DEFESA VEGETAL ANDEF. Defesa vegetal. fevereiro de 2006. 3 p.

BRIGHENTI, A. M. et al. Período de interferência de plantas daninhas na cultura do girassol. Planta Daninha, v. 22, n. 2, p. 251-257, 2004.

CARAVALHO, F. T.; VELINI, E. D. Período de interferência de plantas daninhas na cultura da soja. I - Cultivar IAC - 11 . Planta Daninha, v. 19, n. 3, p. 317-322, 2001.

COMPANHIA NACIONAL DE ABASTECIMENTO CONAB, 2009. Disponível em: <http://www.conab.gov.br/ conabweb/download/safra/3graos_08.09.pdf>. Acesso em: 15 jan. 2009

FREITAS, R. S. et al. Período de interferência de plantas daninhas na cultura da mandioquinha-salsa. Planta Daninha, v. 22 , n. 4 , p. $449-506,2004$

GAZZIERO, D. L. P. As plantas daninhas e soja resistente ao glyphosate no Brasil. In: SEMINÁRIO-TALLER IBEROAMERICANO-RESISTÊNCIA A HERBICIDAS Y CULTIVOS TRANSGÊNICOS, Colonia del Sacramento. Ponencias. La Estanzuela: INIA, 2005. CD-ROM.

KISSMANN, K. G. Plantas infestantes e nocivas. 2.ed. São Paulo: Basf Brasileira, 1997. Tomo 1. p. 415-420. 
KOSLOWSKI, L. A. et al. Interferência das plantas daninhas na cultura do feijoeiro comum em sistema de semeadura direta Planta Daninha, v. 20, n. 2, p. 213-220, 2002.

MELO, H. B. et al. Interferência das plantas daninhas na cultura da soja cultivada em dois espaçamentos entre linhas Planta Daninha, v. 19, n. 2, p. 187-191, 2001

MESCHEDE, D. K. et al. Período crítico de interferência de Euphorbia heterophylla na cultura da soja sob baixa densidade de semeadura. Planta Daninha, v. 20, n. 3, p. 381-387, 2002.

NEPOMUCENO, M. et al. Período de interferência das plantas daninhas na cultura da soja nos sistemas de semeadura direta e convencional. Planta Daninha, v. 25, n. 1, p. 43-50, 2007.

PITELLI, R. A. Interferência de plantas daninhas em culturas agrícolas. Inf. Agropec., v. 11, n. 129, p. 19-27, 1985

PROCÓPIO, S. O. et al. Absorção e utilização do fósforo pelas culturas da soja e do feijão e por plantas daninhas. R. Bras. Ci. Solo, v. 29, n. 3, p. 911-921, 2005
RADOSEVICH, S. R.; HOLT, J.; GHERSA, C. Weed ecology: Implications for management. 2.ed. New York: John Wiley \& Sons, 1997. 589 p.

RODRIGUES, B. N.; ALMEIDA, F. S. Guia de herbicidas. 5.ed. Londrina: 2005. $591 \mathrm{p}$.

RONCHI, C. P. et al. Acúmulo de nutrientes pelo cafeeiro sob interferência de plantas daninhas. Planta Daninha, v. 21, n. 2, p. 219-227, 2003.

SILVA, A. A.; SILVA, J. F. Tópicos em manejo integrado de plantas daninhas. Viçosa, MG: Universidade Federal de Viçosa, 2007. 367 p.

SPADOTTO, C. A. et al. Determinação do período crítico para prevenção da interferência de plantas daninhas na cultura da soja: Uso do modelo "Broken-Stick". Planta Daninha, v. 12, n. 2 p. $187-191,1992$.

VELINI, E. D. Interferências entre plantas daninhas e cultivadas. In: Avances en manejo de malezas en la producción agrícola y florestal. Santiago del Chile: PUC/ ALAM, 1992. p. 41-58. 